\title{
EL PROCESO DE CANONIZACIÓN DE MANUEL PUIG EN EL CONTEXTO DE LA NARRATIVA LATINOAMERICANA FINISECULAR: SISTEMA Y CAMBIO LITERARIOS ${ }^{1}$ \\ Manuel Puig's canonization process in the context of end of the century Latin
} American narrative: system and literary change

\author{
Horacio Simunovic Díaz* \\ Daniela Oróstegui Iribarren**
}

Resumen

El presente trabajo se propone describir e interpretar, en una primera etapa, los mecanismos de canonización literaria de obra y autor en una comunidad cultural específica, la latinoamericana. El caso estudiado es el del escritor argentino Manuel Puig y su obra. La relación interactiva entre contexto cultural, institucionalidad y sistemas de significado social y valoración permite modelar una descripción e intento de explicación de las relaciones de significado entrañadas en la constitución de los repertorios literarios canonizados (Even Zohar), sus criterios de selección, su naturaleza ideológica y la manera en que las prácticas sociales asociadas a este proceso se constituyen por un número variable de prácticas discursivas. Para ello se analiza un conjunto ilustrativo de eventos comunicativos y sus instancias textuales, donde se articulan los cánones literarios y sus efectos culturales: posicionamiento, valoración estética, iconización de autor y de discurso, influencia profesional, tematización crítica y académica, entre otros. Se estudia, por tanto, un caso de integración canónica: la del escritor argentino Manuel Puig en el canon literario de habla hispana y el canon literario universal de fines de siglo y se establece un plano de interacción con los parámetros de construcción canónica de la generación previa, la del llamado "boom literario latinoamericano".

Palabras clave: Postboom, Cánones literarios, Narrativa, Semiosis social.

Abstract

This paper aims to initially describe and interpret the mechanisms of work and author's literary canonization in a specific cultural community, Latin America. The case studied is that of Argentine writer Manuel Puig and his work. The interactive relationship among cultural context, social institutions and systems of social and evaluation meaning allows a description and attempted explanation of the imbued meaning relations in the constitution of the canonized literary repertoires (Even Zohar), their selection criteria, ideological nature and the way in which social practices associated with this process are formed by a variable number of discursive practices. To do this, we analyze an illustrative set of communicative events and their textual instances, through which the literary canon and cultural effects are articulated:

1 Este trabajo forma parte de las actividades de investigación del proyecto Fondecyt Regular № 1121091 "De la 'aceptación' a la resistencia: una anatomía del detalle disciplinario en la narrativa latinoamericana de los siglos XIX y XX”. 
positioning, aesthetic appreciation, author and discourse iconisation, and professional influence, critical and academic thematization, among others. Thus, we study a case of canonical integration by the Argentine writer Manuel Puig into Hispanic and universal literary canon at the end of the century, and set up an interaction with the parameters of canonical construction from the previous generation, the so-called "Latin American literary boom".

Key words: Post-Boom, Literary canons, Narrative, Social semiotics.

\section{PRELIMINAR}

Este estudio propone desarrollar una mirada interdisciplinaria acerca de asuntos que normalmente se han estudiado dentro de los márgenes de disciplinas específicas. En este caso se intenta estudiar un fenómeno literario sin acudir únicamente a las propiedades intrínsecas de obras, particularidades biográficas de autores o comparaciones deterministas entre ambos y sus contextos de producción o recepción.

El fenómeno en estudio es de carácter discursivo y semiótico-social (Halliday, Van Leeuwen) y, por lo mismo, inevitablemente interdisciplinario. No basta con aplicar teorías y métodos semióticos a un objeto como si tal instrumental fuera autosuficiente para abordar cualquier temática, por compleja y heterogénea que esta fuera. Por ello, necesariamente se habrán de intercalar herramientas y procedimientos de los campos de saber que entran en juego, como mucho menos: lingüística, literatura y análisis discursivo.

Los textos asumidos socialmente como literarios se sitúan en un contexto de prácticas sociales cuya relación con las demás prácticas sociales y su definición como actividad específica ha cambiado con el transcurso de la historia y es distinta de cultura a cultura. Lo que podríamos llamar "sistema literario" (Even-Zohar, 1990) no se forma, compone o sostiene por la presencia y circulación única de textos literarios, sino por el entrecruzamiento o contacto de diferentes discursividades como la crítica académica, la crítica periodística, el discurso de los pares profesionales (la comunidad de escritores), el discurso pedagógico, el discurso editorial, el discurso metaliterario de los mismos autores, etcétera. Meletinsky habla de "hecho literario" para referirse no solo a la obra sino al contexto, al público, sus antecedentes, su recepción, sus influencias, lo que decanta en un problema de identificación a la vez de "diferenciación progresiva de lo literario en el transcurso de la historia (Angenot, 17).

Por ello, los problemas relativos al canon literario o los cánones literarios, los procesos de canonización, las listas de obras y autores formantes de esa realidad histórico-cultural y demás instancias de definición de fronteras, inclusiones y exclusiones, tienen una naturaleza heterogénea y compleja, derivada de la dinámica relación de roce, ajuste, filiación o pugna entre las distintas instancias discursivas que participan de su formación.

La proliferación de estudios y opiniones en torno a las problemáticas vinculadas con el canon -o los cánones- demuestra "el desplazamiento de las preocupaciones por el sentido de la obra literaria a la propia teoría y sus ejecutantes, 
lo que favorece los acercamientos al hecho literario desde lo institucional y desde ámbitos colindantes" (Pozuelo y Aradra, 15 y ss.). Sin plantear, necesariamente, que la teoría literaria demuestre con ello un estado de crisis, se puede suponer que la reflexividad del gesto teórico se debe al menos a un ímpetu crítico y exploratorio de las condiciones epistemológicas del ejercicio disciplinar y a la vez es el resultado de una relación más desenvuelta con el contexto sociohistórico y cultural, tanto de la práctica teórica como de los discursos que constituyen el supuesto objeto central de estudio: los textos o discursos literarios.

El caso estudiado es el del escritor argentino Manuel Puig y su obra, pero no es nuestro propósito explicar estéticamente las cualidades que la obra de Puig poseería para justificar dicha valoración, ni tampoco explicar las relaciones sociales, en cuanto tales, que derivarían en dicha valoración, pensada, esta vez, como un efecto no de las propiedades intrínsecas de sus obras, sino de las coordenadas semióticas entrelazadas con las económico-políticas de su aparición, mantención y relieve social. En el sentido de mostrar, con unos pocos ejemplos, el concierto de discursos suscitados en torno a su valoración como escritor y la de su obra como literatura relevante.

De hecho, seguramente, ambos proyectos podrían emprenderse y esperar resultados fructíferos sin temor a forzar la realidad estudiada; sin embargo, de lo que se trata aquí es de ofrecer una explicación de las relaciones de interacción que el discurso literario del autor desarrolla con otros discursos para los cuales representa una categoría tópica central y que incluyen los discursos de Puig como entidades representadas según esquemas de valoración, en contextos a su vez representados o construidos discursivamente como favorables circunstancias de fondo.

El texto que ahora sigue es solo una pequeña muestra, un esbozo provisorio del ejercicio planteado por la investigación sugerida y, en ese sentido, solo deja ver unos pocos asuntos, una parte del marco teórico y del método y, por tanto, solo una mínima parte de los posibles resultados. Este escrito tiene, entonces, un propósito puramente introductorio y es solo una mínima muestra de lo planteado, a la espera de una investigación más amplia.

\section{LOS CÁNONES Y EL HECHO LITERARIO}

1.1. Es importante destacar que dentro de las múltiples cuestiones planteadas por esta problemática, una de las más notorias y relevantes para comprender el funcionamiento de los cánones literarios en los últimos siglos es el estudio de la evolución de la noción de autor vinculada a la literatura (Meletinsky, 18). Noción que, para la historia literaria tanto de las obras como de los hechos, instituciones y discursos relacionados con ellas, adquiere prominencia mayor desde el romanticismo. Por eso hemos pensado que lo canonizado no son solo las obras literarias sino también los autores. Se genera así un culto a la personalidad y el oficio míticos de los autores y estos forman, junto a sus obras y a veces junto a otros autores, un mismo fenómeno. 
Al revés de la dinámica adoptada por las ideas que plantean la desaparición del autor (Barthes, Foucault), la relación que tienen las obras canonizadas con las figuras autoriales canonizadas es evidente. No son solo las obras las que se incorporan al canon o se desintegran del mismo, sino también sus autores. Muchas veces es la figura autorial como signo o emblema la que promueve por añadidura o "arrastre" la inclusión canónica.

Hoy el significado complejo evocado por los cánones es inseparable de esta concentración dominante en la figura del autor, si bien es probable que nos encontremos ahora en un período deflacionario de dicho valor en el contexto general del sistema literario, si pensamos en los efectos todavía insospechados de la propagación industrial del oficio literario mediante la llamada "literatura de género" o paraliteratura (Wischmann, Eco, Zubieta) y su expresión disgregada, colectivizada, interactiva y popular en la red.

Como sea, la consideración de un canon o múltiples cánones entraña siempre la actualización de sistemas de inclusión y segregación complementarios, pero también dinámicos. Los regímenes de valores que organizan los cánones están sujetos a la volubilidad que les imprime la historia y sus revoluciones, estancamientos y dispersiones.

La postulación del canon literario es coextensivo con la definición misma del hecho literario, al punto que su constitución revela los límites culturales de inteligibilidad de los hechos relacionados con la práctica literaria, en especial aquellos que más centralidad comportan en ella: la escritura de obras literarias y los distintos discursos y prácticas metaliterarios que anteceden, coexisten con y suceden a las obras.

1.2. Para muchos estudiantes noveles de literatura, la noción de literatura es un "dado", un término cuyo referente está garantizado al punto de justificar su propio interés personal en el asunto. Sin embargo, dentro del terreno mismo de los estudios literarios y en otros campos como la filosofia, la historia o la lingüística, la fuente de dicha seguridad es puesta en cuestión y el objeto "literatura" se desdibuja, se diluye en otros términos o se complica en definiciones y posturas heterogéneas.

El término "literatura" proviene del plural latino litterae, letra, en el sentido de "cosas hechas con letras". La noción misma de literatura (como práctica discursiva asociada a unas convenciones distintas de las demás formas de comunicación) no es anterior al siglo XVIII. En español, la palabra literatura, de una forma cercana a como se comprende hoy, se empezó a desarrollar en el siglo XVIII.

Paralelamente a la clasificación tradicional, si bien modificada, de las Artes liberales y las Artes mecánicas, se formulan -debido a la influencia francesa- nuevas clasificaciones que empiezan a marcar los inicios de la separación entre Bellas o Buenas Artes y las Ciencias. Elementos innovadores pueden hallarse en las obras de Ignacio de Luzán (La poética o reglas de la poesía en general y de sus principales especies, 1737) y Benito Jerónimo Feijoo (Teatro crítico universal, 1726-1740 y las Cartas eruditas y curiosas, 1742-1760). Resulta que al mismo tiempo cuando se 
empieza a distinguir entre Bellas o Buenas Artes y Ciencias y se intenta una diferenciación interna de las Buenas Artes, de donde surge el subgrupo de las Artes plásticas, empieza a imponerse el empleo de Buenas o Bellas Letras. Estos términos, por un lado, se emplean como sinónimos -igual que Literatura y Letras- con referencia a una actividad intelectual, en el sentido de erudición. Por otro lado, se usan Buenas o Bellas Letras con referencia al objeto de esta actividad intelectual, o en sentido amplio, abarcando la totalidad de disciplinas de las Artes y las Ciencias, o en sentido estricto, designando un delimitado grupo de materias, las litterae humaniores, es decir, las que cumplen con el ideario humanístico renacentista del 'hablar bien', 'pensar bien' y 'vivir honestamente' (Gunia, 257).

A nivel crítico, por ejemplo en el ámbito angloparlante, el sentido estético de la palabra "literatura" solo se consolidó en el siglo XIX y estuvo íntimamente ligado al significado nacionalista de expresiones como "Literatura Inglesa". Ya en el siglo XX, las distintas teorías y enfoques han rondado, en general, en un sentido muy similar a este (Fowler en Coyle et al, 5).

Actualmente la literatura supone un canon o unos cánones y la definición misma del uso del término, como la programación de su ámbito cultural, dependen de la organización canónica inconstante de unos conjuntos de obras, sus autores y los sistemas de valores que los propugnan.

El canon literario, socialmente, inspira no solo conservación y defensa, sino también suspicacias y rechazo. Piglia decía, en respuesta a la pregunta ¿Quién es Roberto Arlt?: "Alguien que no es un clásico, es decir, alguien cuya obra no está muerta. Y el mayor riesgo que corre hoy la obra de Arlt es el de la canonización" (21). El término ha adquirido en algunos círculos sociales, entonces, este matiz negativo y se le considera una amenaza para la "vitalidad" de la literatura y el síntoma de la fosilización estética. En realidad, el canon parece una relación ineludible para las prácticas literarias, sus agentes y sus productos, lo que quiere decir que no responde a voluntades individuales, sino que tiene un comportamiento sistémico, aunque metamórfico, cambiante y muchas veces impredecible.

\section{VISIONES SISTÉMICAS DEL LENGUAJE Y LA LITERATURA}

2.1. Las teorías son, por decirlo de algún modo, el diseño que damos a cualquiera de las formas del conocimiento; sea científico, filosófico, literario e inclusive en el caso del conocimiento enciclopédico cotidiano que nos permite operar en el entorno inmediato. Podríamos hablar de una especie de teoría o encuadre cognitivo, portador de las claves básicas para comprender la existencia. La teoría es, entonces, la instancia mediadora de toda posibilidad de conocimiento humano y es el molde y sostén de la observación y la percepción, como también de las operaciones con el entorno.

Las teorías sistémicas en las distintas disciplinas plantean un paradigma integrador de los fenómenos y procesos de estudio. Ellas evitan atomizar dichos 
elementos, efecto propio de las perspectivas esencialistas. Del mismo modo, una teoría sistémica del canon va a evitar convertir al canon en una entidad homogénea o en una propiedad intrínseca de los objetos o hechos a los que se aplique. Los hechos y las instancias puntuales solo pueden explicarse, sistémicamente, aludiendo al nivel superior de organización en que se integran.

El pensamiento sistémico es, en esencia, transdisciplinario, debido a que se extiende desde disciplinas como la cibernética, la biología y la sociología a disciplinas como la lingüística o los estudios literarios. El sistema es un complejo formado por elementos ordenados según una determinada trama de relaciones que otorga al sistema unidad propia (Maldonado, 15).

2.2. En el ámbito lingüístico, adopta un carácter interdisciplinario, ya que su interés por abarcar holísticamente los fenómenos estudiados lleva a la incorporación de perspectivas y herramientas provenientes de campos de estudio colindantes. La expresión más patente del pensamiento sistémico aplicado al lenguaje se produjo en el ambiente anglosajón. Entre las décadas de 1960 y 1970 se generó una escuela interdisciplinaria, aplicada al estudio del lenguaje, en torno al trabajo de M.A.K. Halliday (El lenguaje, Functional grammar), quien a su vez reconoce la influencia de su maestro J.R. Firth, del antropólogo Bronislaw Malinowski, el Círculo lingüístico de Praga, Louis Hjelmslev, entre otras variadas fuentes de inspiración. El enfoque recibió el nombre de Lingüística Sistémico-Funcional ${ }^{2}$ (LSF). Este modelo tuvo un desarrollo original en el ámbito gramatical, para luego extenderse a múltiples áreas de interés como la adquisición de lenguas, el estudio de las valoraciones, las variedades registrales y genérico-discursivas, los estudios ecocríticos, la estilística, la lingüística computacional, etcétera.

Según esta perspectiva, la lengua es una semiótica social, en el sentido de que en el uso de la lengua se realizan los significados culturales y sus esquemas de organización. La gramática viene a ser la realización de los distintos tipos de significados (ideativos, interpersonales y textuales) y, a su vez, esos significados instanciarán diversas configuraciones del contexto situacional en la forma de registros, los que realizarían en situaciones concretas de comunicación los patrones genérico-discursivos, en cuanto manifestación de las metas sociales que los miembros de una comunidad cultural persiguen en sus interacciones sociales.

2.3. El sistema literario, por su parte, es un concepto que tiene sus orígenes en el formalismo ruso, mediante autores como Tinianov y Jakobson. Tinianov se opone a la teoría del texto literario como resultado de un acto aislado y postula su dependencia de los procesos comunicativos y del contexto tradicional en que se produce. De esta forma, el fenómeno literario se articula en una dimensión sincrónica por su valor diferencial frente al uso cotidiano de la lengua y en una dimensión diacrónica en cuanto a su relación con las normas literarias vigentes y sus sistemas de restricción y habilitación (Maldonado, 16).

\footnotetext{
${ }^{2}$ En la década de 1960 se habló de "contextualismo británico" y de "lingüística crítica".
} 


\section{TEORÍA POLISISTÉMICA DE LA LITERATURA}

3.1. La Teoría de los Polisistemas (Polysystems Theory) se vincula con el trabajo realizado por un grupo de estudiosos de la Universidad de Tel Aviv, con Itamar Even-Zohar a la cabeza y se basa en los postulados del funcionalismo dinámico del Formalismo Ruso y la teoría social de la literatura y el arte de Pierre Bourdieu (Maldonado, 1999). "In polysystem theory, however, the term is already a commitment to the concept of 'system' in (dynamic) functionalism, i.e., the network of relations that can be hypothesized for a certain set of assumed observables ('occurrences'/"phenomena'). This implies that 'the set of assumed observables' is not an independent 'entity in reality', but dependent on the 'relations' one is prepared to propose" (Even Zohar, 27).

La dependencia de las interrelaciones en que aparecen los fenómenos y las entidades hace que esta teoría plantee de manera muy ilustrativa la heterogeneidad genética no solo de los cánones literarios sino de las mismas obras literarias, que son, por último, el conjunto de instanciaciones del sistema en un momento histórico y una cultura dadas."The network of relations that is hypothesized to obtain between a number of activities called 'literary', and consequently these activities themselves observed via that network. Or: The complex of activities, or any section thereof, for which systemic relations can be hypothesized to support the option of considering them "literary"' (28).

El sistema literario se trata, entonces, de una red de relaciones obtenidas con el fin de hipotetizar las actividades llamadas literarias, pero también las actividades mismas que pueden ser hipotetizadas por medio de esa red de relaciones. "THE" literary system does not "exist" outside the relations contended to operate for/in it. So whether we use a conservative conception of a "system", or adopt the dynamic concept of it (polysystem), there is no a priori set of "observables" that necessarily "is" part of this "system".

3.2. El sistema literario no existe fuera de las relaciones sostenidas para operar en él. Por lo que, ya sea que usemos una concepción conservadora de "sistema" o adoptemos un concepto dinámico (polisistema), no existe un conjunto predeterminado de "observables" que necesariamente "sean" parte del "sistema".

Por tanto, el asunto del canon, los cánones o los procesos de canonización tienen una naturaleza sistémica y sociosemiótica; en el sentido de que -no solo en los fenómenos socioliterarios estudiados sino en toda práctica comunicativa- la gente usa determinados recursos semióticos para producir e interpretar sentido, que, a su vez, es también una forma de producirlo (Van Leeuwen, xi). Esto implica adoptar una perspectiva contraria a la postura totalizadora de las ciencias que operan como si estuvieran por fuera de los problemas que estudian, como si se ubicaran más allá de las productoras de sentido que estudian (Thibault, 4) 
El problema de los cánones y los procesos de formación asociados a ellos ha sido estudiado dentro de la teoría polisistémica y se perfilan desde su enfoque algunos replanteamientos útiles para repensar las bases teóricas y para diseñar las estrategias del estudio de los cánones. "In this context, thinking about canons is, in fact, thinking about the "great literary tradition": the durability of celebrated past works and figures, and their invocation and reevaluation in order to establish the value of the contemporaries" (Even-Zohar, 512).

Las propiedades que la perspectiva sistémica (o polisistémica) favorecen no son propiedades inherentes a los objetos o a los procesos, entendidos como entidades definitivas, sino que remiten a propiedades dinámicas y asociadas a cada caso particular. "....as a functionalist theory, Polysystem Theory dissociates, in principle, properties (i.e., 'canonicity') from their carriers (i.e., canonical items); 'canonicity' is believed to be a function which pertains to the theoretical notion of 'system', whereas the material to which it is attributed varies in each and every specific case study" (512)

Como Even Zohar indica en nota a pie de página (16), "esta es, en efecto, la razón por la que la Teoría Polisistémica tiende a evitar el atributo "canónico", que puede erróneamente llevar a pensar que se trata de una propiedad intrínseca y prefiere, en cambio, el atributo "canonizado" que implica que la canonicidad involucra una actividad ejercida sobre un cierto material.

Visto desde esta perspectiva, el problema aquí planteado se observa en conexión con los factores que entran en juego en su configuración como discurso. $\mathrm{O}$ sea, se destaca la concurrencia de discursos diferentes, conectados con la obra y figura autorial y en función de la constitución de los sistemas de valor, jerarquización y membresía que caracterizan a los cánones y sus procesos dinámicos.

\section{EL BOOM COMO CANON}

4.1. Sheffy (1990) sostiene que, desde cierto punto de vista, las nociones de literatura y canon parecen confundirse y referir a una misma realidad. La literatura se propone como conjunto de obras y autores relevantes, como tradición generativa de estilos y estrategias, como lenguaje social relevado y, en última instancia, como norma de afiliación y discriminación.

El fenómeno literario bautizado como "boom latinoamericano" -movimiento, confluencia histórica accidental o selección crítica- posee la suficiente presencia, figuración y pregnancia para ser considerado uno de los cánones literarios más importantes de la historia de la literatura latinoamericana y mundial. Los esfuerzos por justificar la denominación archiconocida que este fenómeno literario ostenta se registran desde sus orígenes históricos y quizá, en perspectiva, la mejor forma de comprender su identificación responda más al reconocimiento de un lugar común cultural y a la herencia de una construcción crítica legendaria que a la organización de una justificación precisa y lógicamente definida. 
Oviedo dice que se trata de una denominación muy poco literaria, pero que todos la reconocen fácilmente y la usan defensores y detractores (Oviedo, 199). El autor opina que el boom fue "una notable conjunción de novelas a mediados de la década del sesenta y una revaloración de otras, no menos importantes, que habían sido soslayadas o leídas en distinto contexto" (300). Queda claro entonces que la denominación resulta una construcción no plenamente finalizada, que tuvo mayor suerte que otras formas de llamar más o menos al mismo conjunto de obras y autores y ejerce su influencia en una especie de área o entorno de irradiación que propicia la observación, desde su perspectiva, de autores y obras anteriores y posteriores; tanto para postular lazos de influencia desde (anteriores) y hacia (posteriores) como para establecer límites y distinciones respecto de otros conjuntos también supuestamente previos o ulteriores.

José Donoso indica en su obra Historia Personal del Boom (1972) que

si la novela hispanoamericana de la década del sesenta ha llegado a tener esa debatible existencia unitaria conocida como el boom, se debe más que nada a aquellos que se han dedicado a negarlo; y que el boom, real o ficticio, valioso o negligible, pero sobre todo confundido con ese inverosímil carnaval que le han anexado, es una creación de la histeria, de la envidia y de la paranoia: de no ser así el público se contentaría con estimar que la prosa de ficción hispanoamericana - excluyendo unas obras, incluyendo otras según los gustostuvo un extraordinario período de auge en la década recién pasada (9).

El canon construido con el nombre de "boom latinoamericano" se forja en un contexto histórico especial de atracción por, y esperanza en, la Revolución Cubana y de difusión de un cierto latinoamericanismo, asociado al predominio de las ideas de izquierda entre ciertos sectores sociales y a la creciente ola de participación social en los distintos países de Latinoamérica. Se pueden invocar otras características históricas de naturaleza más global, pero las mencionadas son las que tradicionalmente se vienen reconociendo como influencias inmediatas del fenómeno.

La manera en que se termina de constituir es heterogénea y compleja y las formaciones discursivas formantes del "discurso del boom" son variadas: la crítica literaria académica, la crítica periodística, el discurso de los escritores y sus pares, el discurso pedagógico, etcétera.

Algunas de las cualidades atribuidas a las obras y autores, las que pueden entenderse como las propiedades culturales que otorgan prominencia al fenómeno, se destacan discursivamente en las instanciaciones de diversos discursos. Son el resultado de la manera en que el fenómeno en su conjunto o sus ejemplos particulares son representados en esos discursos y dependen del nivel de estatus sociocultural que comportan. La opinión de José Donoso es una entre muchas otras, que concuerdan o disienten en torno al tema, pero que contribuyen, cada una a su manera en conformar el efecto boom. Dentro de los discursos levantados por los propios escritores, además del ensayo de Donoso, está el acercamiento de otros escritores involucrados con el 
boom, como es el caso de Carlos Fuentes. Entre los estudios académicos más destacadas y, además, cercanos temporalmente, está el conocido libro de Emir Rodríguez Monegal.

Hubo una gran riqueza creativa acompañada de una gigantesca masa de lectores. Según Oviedo, "el boom marca un punto decisivo en el que cambia, para siempre, la producción, consumo y circulación de nuestra literatura" (302). El boom tiene una influencia de al menos un par de décadas en el gusto lector y en el sistema literario latinoamericano, sin contar la influencia ejercida sobre la práctica literaria fuera de Latinoamérica. Sin embargo, en la década de los setenta y en adelante, a pesar de que los autores principales del boom continuaban su ejercicio creativo, comienzan a vislumbrarse otros proyectos narrativos que compiten con los de la generación anterior e introducen varios cambios, no solo en el uso del lenguaje, sino también en la misma temática de las obras.

Los integrantes, también discutidos, de la generación que normalmente la crítica llama postboom tienen en común la exploración de los límites entre la cultura canonizada y la cultura popular. Son, en sí mismos, ejemplos de un gesto metaliterario de revisión de los parámetros que definen el ejercicio literario como práctica prestigiosa y de inclusión del discurso popular y las formas industrializadas de la cultura en sus obras. Algunos de los autores comúnmente incluidos son los chilenos Antonio Skármeta, Ariel Dorffman e Isabel Allende; el peruano Alfredo Bryce Echeñique; el escritor cubano Severo Sarduy; y el escritor argentino Manuel Puig, cuya presencia canonizada (o no) cuestionamos en este estudio.

\section{MANUEL PUIG EN EL CANON}

5.1. En este apartado no se realizará un análisis exhaustivo de un corpus, a su vez exigente, de discursos comprometidos en el proceso de canonización de la figura y la obra de Puig, pero sí acertaremos a mostrar una pequeña muestra de cómo analizar el tipo de representación semiótica que ciertos discursos críticos hacen del caso Puig. Dichos discursos críticos representan solo una parte del concierto discursivo que habría de poner en juego para dar cuenta cabal de la red semiótica comprometida en la construcción de cánones o, más coherentemente, en la definición de procesos de canonización.

Primero se revisan, a partir del discurso mediado de críticos contemporáneos nuestros, el rechazo recibido por Puig y su obra desde sectores canonizados del mundo literario. Lamentablemente, no se cuenta con las fuentes originales de dichas críticas, por el hecho de tratarse de eventos comunicativos orales de los que no existe otro registro que la memoria de los testigos. Son, en ese sentido, testimonio actual de discursos pretéritos.

5.2. La escritura de Manuel Puig despertó interés y rechazo en iguales medidas desde un comienzo. A fines de la década del sesenta (1968) publica su primera obra, originalmente pensada como un guión de cine, La traición de Rita 
Hayworth. Juan Goytisolo, en una columna escrita para el diario El País, dice haber leído el manuscrito de un desconocido un día, por consejo de un amigo: "Pocas veces en mi vida he calado en un texto literario de un desconocido con tanta sorpresa y delicia. Al cabo de la lectura, tenía el pleno convencimiento de hallarme ante un auténtico novelista, atrapado, como lector, en las redes de un mundo originalísimo y personal" (en línea).

En su columna, el escritor español intenta, justamente, expresar el enorme rechazo recibido originalmente por Puig y su obra, de parte del establishment literario de la época. La novela fue postulada para el premio "Biblioteca Breve" de la Editorial Seix Barral en Barcelona. Goytisolo la había llevado a Carlos Barral ${ }^{3}$, pero él no le tomó el menor interés, por lo que a pesar del éxito que tuvo en el jurado, la oposición del editor catalán determinó que la obra no obtuviera el premio. Luis Goytisolo, hermano de Juan, miembro del jurado en esa ocasión, dimitió como gesto de rechazo a la actitud prepotente de Barral. Por último, a pesar de haber estado más o menos comprometida la publicación de la obra, esta no se produjo y solo vino a ser publicada con posterioridad en Buenos Aires.

Goytisolo, en el mismo texto, declara "Su impresión personal de Manuel, quien, ingenuamente había corrido a verle a Barcelona en calidad de finalista, fue tan negativa como tajante. Con su probado olfato literario, decidió que aquel argentino afeminado, vulnerable y frágil no era un escritor digno de figurar en el prestigioso catálogo de la editorial" (en línea).

Más tarde, Ariel Schettini relata el que considera el primer episodio de lectura de la obra de Puig (seguramente desconocía el que se ha relatado antes): "En 1968, el jurado del concurso de novela de la revista Primera Plana se divide entre Severo Sarduy (que defiende Boquitas Pintadas como la ganadora) y Mario Vargas Llosa y Juan Carlos Onetti que la desestiman. Finalmente, se dice que Onetti dio el veredicto final: la voz del escritor estaba tan fundida con la de sus personajes que se corría el riesgo que el escritor tuviera el mismo registro verbal de sus personajes" (Schettini, 211). Puig mismo, citado por Schettini, se refirió al suceso: "Cuando la presenté a un concurso de novela en Buenos Aires, Juan Carlos Onetti no quiso darme el premio porque dijo que yo copiaba a tal punto la cultura popular que no se podía saber cómo era realmente mi verdadera escritura" (211).

5.3. Ya en una época más amable para Puig, su obra despierta aún opiniones encontradas entre sus pares y los críticos:

Aunque el juicio afirmativo sobre los valores estéticos de la literatura de Puig domina dentro del campo de la crítica argentina, hispano y norteamericana, no se trata de un juicio unánime. Para Juan José Saer y Rafael Conte, las novelas de Puig responden de un modo desafortunado, por lo anacrónico, a las exigencias

\footnotetext{
${ }^{3}$ Carlos Barral fue un poeta, senador y editor español que heredó la Editorial Seix Barral de Barcelona, fundada por sus padres. Creó varios premios, entre ellos el de Biblioteca Breve. Fue también el principal propulsor editorial del boom latinoamericano. Murió en 1989.
} 
estéticas de la modernidad; enfrentado a esas exigencias, Puig reacciona, según estos autores, desde una sensibilidad costumbrista (Giordano, 18).

Giordano insiste en ello y recupera las palabras de Beatriz Sarlo, quien opina que la obra de Puig no logra distanciarse de la trivialidad y la frivolidad de los géneros 'subculturales' y "se presenta con la soltura con que se exhibe un gusto y no una posición moral en el campo estético (Sarlo, citado por Giordano, 22.).

Por lo demás, la vistosa aceptación recibida por Puig y su obra en el discurso de otros autores, en épocas posteriores, no representa una simple contradicción aporética, sino más bien una complementariedad dinámica que incluso contribuyó a la saliencia estética que tuvo, con el tiempo, el autor argentino.

Como el mismo Giordano destaca, numerosos críticos realizaron la contrapostura de los juicios negativos antedichos y "demostraron la modernidad de las experiencias narrativas de Puig y su eficacia crítica para la crítica ideológica desalienante y desmitificadora" (18), aunque como el mismo Giordano indica, ambas posturas, en general, no hacen sino confirmar la misma estructura ideológica, confiada en la pertinencia de la polaridad entre "cultura letrada o alta" y "cultura de masas".

5.4. Sin embargo, en vez de avanzar al estudio de un momento de la crítica más feliz para el caso del escritor estudiado, procedemos a mostrar la forma en que estos textos construyen la realidad del fenómeno discursivo literario de Manuel Puig en el concierto de restricciones y habilitaciones culturales que caracterizan los procesos de canonización, en todo su dinamismo. En función de no extender este trabajo más allá de los límites propuestos, mostramos, mediante unas pocas herramientas de análisis lingüístico, la manera cómo se construyen los significados culturales en sus instanciaciones textuales, mediante un par de los juicios negativos ya mostrados.

Postulamos que el dialogismo de los textos citados contribuye a entrever la pugna ideológica de fondo y a ofrecer la perspectiva de dos fases críticas, respecto del autor y su obra, que se suceden. Para ello se hará un análisis semántico ideacional de las estructuras lingüísticas componentes de un par de instanciaciones críticas negativas y luego de ver cómo se organizan los significados de dichos textos, se ofrece una mirada a ciertos aspectos del sistema interpersonal y configuración ideológica.

Halliday (Functional grammar) plantea que la lengua es un sistema semiótico que da forma a la cultura, de allí que se considere su enfoque como "semióticosocial". Además, este sistema que funciona biopsicológicamente, pero se justifica por su función social, está organizado triestalmente. $\mathrm{O}$ sea, en tres estratos de distinto nivel de abstracción: el estrato de la expresión (fonografémico) y dos estratos de contenido: el estrato léxico-gramatical y el estrato semántico-discursivo. Según esta lógica, lo que llamamos habitualmente significados, se realizan en las estructuras gramaticales y estas en los sonidos (fonos o fonemas) o grafemas de la escritura.

En el estrato semántico, encontramos las llamadas metafunciones: ideacional, interpersonal y textual. Halliday las denomina metafunciones porque van más allá de las funciones específicas que cumple la lengua en situaciones concretas de interacción 
social y corresponden a funciones más o menos universales, comunes a todas (o la mayoría) de las culturas conocidas: representar la realidad (tanto exterior como interior: el mundo físico y mental): metafunción ideacional, servir de herramienta interactiva para sostener relaciones sociales organizadas en cuanto a rol y estatus: metafunción interpersonal, y la metafunción textual, relacionada con el papel que juega el lenguaje en la construcción de enunciados y textos coherentes.

Estos tres sistemas semánticos (las metafunciones) se realizan o codifican en un conjunto de sistemas gramaticales complementarios. La metafunción ideativa se realiza en el sistema gramatical llamado transitividad (y el subsistema de la ergatividad), la metafunción interpersonal se realiza en el sistema gramatical de modo y la metafunción textual se realiza en el sistema temático (tema-rema) en el nivel de la gramática.

En el análisis de la metafunción ideacional, realizada en el sistema gramatical de la transitividad, existen tres tipos de roles semánticos principales: participantes (humanos o no), procesos (de diverso tipo: materiales, mentales, relacionales, existenciales, verbales y de comportamiento) y circunstancias de diversa índole, que representan un rol menos central e incluso su aparición en la estructura de la cláusula es opcional. La denominación que reciben los participantes depende del tipo de proceso en el que se vean involucrados y de la función lógico-representacional que cumplan. Por ejemplo, en los procesos materiales, muy comunes en las narraciones, el rol central lo cumple el ACTOR (coincidente con la función de sujeto gramatical muchas veces, pero más que nada con el agente de la acción) y el objeto constituye la META (O.D.) del proceso (cuando se trata de un rol semántico disgregado de la semántica propia del proceso y ALCANCE cuando la estructura completa la definición semántica del proceso. Existen otros roles que no explicaremos aquí por razones de espacio. En los procesos mentales la misma posición funcional es cumplida por el SENSOR (subjetivo) del proceso mental cuya proyección hacia un objeto se realiza en un FENÓMENO (O.D.). También por economía, no explicamos aquí todos los roles semánticos relativos a todos los tipos de proceso, ni tampoco la desarrollada tipología de circunstancias que determinan eventualmente esos procesos ${ }^{4}$. Los elementos mostrados debieran sugerir el tipo de lógica desarrollada en esta etapa del análisis.

\section{ANÁLISIS}

6.1. Presentamos, someramente, solo una de estas dimensiones: la transitividad, como sistema formal de realización de los significados representacionales de la lengua. De igual forma, aunque sin el debido detalle, que volvería el análisis más exhaustivo pero también demasiado extenso para los propósitos de esta exposición, mostraremos algunos aspectos interpersonales expresados en los textos, por medio de múltiples recursos tanto léxicos como gramaticales.

\footnotetext{
${ }^{4}$ Ver Halliday.
} 
El texto de Goytisolo, más antiguo y más cosmopolita, sirve de referente histórico y cultural internacional:

Su impresión personal de Manuel, quien, ingenuamente había corrido a verle a Barcelona en calidad de finalista, fue tan negativa como tajante. Con su probado olfato literario, decidió que aquel argentino afeminado, vulnerable y frágil no era un escritor digno de figurar en el prestigioso catálogo de la editorial.

Este texto está compuesto por dos estructuras complejas, compuestas cada una por dos cláusulas. En ambos casos se trata de estructuras hipotácticas (subordinadas).

La primera oración o complejo de cláusulas:

Su impresión personal de Manuel, quien, ingenuamente había corrido a verle a Barcelona en calidad de finalista, fue tan negativa como tajante.

Se puede organizar más claramente para el análisis de la siguiente forma:

\begin{tabular}{|l|l|l|}
\hline $\begin{array}{l}\text { Su impresión personal de Manuel, quien } \\
\text { ingenuamente había corrido a verle a } \\
\text { Barcelona en calidad de finalista, }\end{array}$ & fue & $\begin{array}{l}\text { tan negativa } \\
\text { como tajante. }\end{array}$ \\
\hline Portador & $\begin{array}{l}\text { Proceso relacional } \\
\text { atributivo }\end{array}$ & atributo \\
\hline
\end{tabular}

La estructura gramatical del rol semántico del participante involucrado es el de un portador. Esta determinación de rol se debe a la previa definición del proceso, realizado en la estructura del verbo, como proceso relacional atributivo. El otro rol participante expresado en la estructura es de naturaleza diferente: es un atributo.

Los procesos relacionales, según Halliday, son procesos abstractos que sólo representan relaciones entre entidades. El subtipo atributivo indica que esta relación se da entre dos tipos de participantes distintos: uno de ellos es el portador de un atributo y el otro es el atributo mismo.

Si tomamos en cuenta que, desde un punto de vista genérico-discursivo, el fragmento es un relato anecdótico, es significativo ver que lo que se relata es un evento construido como una relación expresada en términos valorativos. Lo relacionado es un proceso mental convertido en entidad (su impresión personal de Manuel) y la valoración que el hablante (Goytisolo) da de esa entidad. La frase sustantiva "su impresión personal de Manuel" constituye una metáfora gramatical por nominalización. El proceso mental vivido por Barral de "impresionarse con Manuel" se nominaliza. Según Halliday, el recurso de las metáforas gramaticales es de uso común y muy frecuente en determinados tipos de textos.

Las nominalizaciones realizan un empaquetamiento cognitivo de procesos o conjuntos de procesos que, si fueran expresados mediante recursos más "congruentes" o habituales, complicarían la sintaxis por la proliferación de cláusulas y sus procesos realizados según estructuras verbales (predicaciones). 
Además, la entidad está construida gramaticalmente de manera compleja. En la estructura encontramos una cláusula incrustada de función adjetiva (quien ingenuamente había corrido a verle a Barcelona en calidad de finalista) que representa un evento distinto, de tipo material. Los procesos materiales, según Halliday, son procesos del mundo físico generalmente, pero también incluye en esta categoría otros procesos más abstractos del mundo económico, político o administrativo.

\begin{tabular}{|l|l|l|l|l|}
\hline quien & ingenuamente & $\begin{array}{l}\text { había corrido } \\
\text { a verle }\end{array}$ & a Barcelona & $\begin{array}{l}\text { en calidad de } \\
\text { finalista }\end{array}$ \\
\hline Actor & $\begin{array}{l}\text { Circunstancia de } \\
\text { manera }\end{array}$ & $\begin{array}{l}\text { Proceso } \\
\text { material }\end{array}$ & $\begin{array}{l}\text { Circunstancia de } \\
\text { lugar }\end{array}$ & $\begin{array}{l}\text { Circunstancia } \\
\text { de rol }\end{array}$ \\
\hline
\end{tabular}

En esta subescena Puig corrió a ver a Barral a Barcelona en calidad de finalista. Son varios elementos los que le dan riqueza expresiva: Puig corre, metafóricamente, a Barcelona a ver a Barral y lo hace ostentando determinada dignidad: finalista. El verbo que realiza el proceso tiene una estructura cercana a la de una perífrasis ingresiva en tiempo pretérito (había corrido a verle). Las llamadas perífrasis ingresivas tienen la característica de expresar una acción como a punto de realizarse, por ello, el verbo personal es normalmente el verbo ir y aparece en presente; sin embargo, Goytisolo usa el verbo correr conjugado, lo que ofrece un matiz de gradación que expresa la intensidad de la acción, desde un punto de vista valorativo. La cláusula concentra en sí misma varios aspectos de representación que proyectan la interpretación del rol participante (realizado en el Actor de referente Manuel Puig) como un sujeto en posición de desventaja de estatus (corre a ver al editor: esperanza y ansiedad) y de personalidad ingenua (ingenuidad). Se articula un microsistema representativo muy coherente para construir la figura del escritor y su peripecia fallida.

La segunda oración: "Con su probado olfato literario, decidió que aquel argentino afeminado, vulnerable y frágil no era un escritor digno de figurar en el prestigioso catálogo de la editorial" también es una oración compleja, compuesta por dos cláusulas.

\begin{tabular}{|l|l|l|l|}
\hline $\begin{array}{l}\text { Con su probado } \\
\text { olfato literario }\end{array}$ & decidió & $\begin{array}{l}\text { que aquel argentino } \\
\text { afeminado, vulnerable y frágil } \\
\text { no era un escritor digno de } \\
\text { figurar en el prestigioso } \\
\text { catálogo de la editorial }\end{array}$ \\
\hline $\begin{array}{l}\text { Circunstancia de } \\
\text { Instrumento }\end{array}$ & $\begin{array}{l}\text { Proceso } \\
\text { Material }\end{array}$ & Actor & Meta \\
\hline
\end{tabular}

En esta estructura tenemos una circunstancia de instrumento como punto de arranque. $\mathrm{O}$ sea, lo primero es la representación de la facultad usada para realizar una acción material que sugiere ciertos aspectos mentales. En principio, muchos estarían 
de acuerdo en clasificar la semántica del verbo "decidir" como mental, pero en el contexto discursivo estudiado tiene el sentido de una acción administrativa, de poder, que deriva en un efecto material: la pérdida del premio. "Decidió" adopta el sentido de una acción discriminatoria resultante en un perjuicio para el escritor.

Esta vez, la mayor complejidad no se encuentra en el sujeto sino en el predicado. En este caso, es el Objeto (lo decidido, el resultado de la decisión) el que se estructura de manera compleja, en la forma de una cláusula subordinada sustantiva.

\begin{tabular}{|l|l|l|l|}
\hline que & $\begin{array}{l}\text { aquel argentino } \\
\text { afeminado, } \\
\text { vulnerable y frágil }\end{array}$ & no era & $\begin{array}{l}\text { un escritor digno de } \\
\text { figurar en el } \\
\text { prestigioso catálogo } \\
\text { de la editorial. }\end{array}$ \\
\hline Portador & $\begin{array}{l}\text { Proceso } \\
\text { Relacional } \\
\text { Atributivo }\end{array}$ & Atributo \\
\hline
\end{tabular}

En esta cláusula, el Portador es complejo, ya que se estructura en la forma de una frase nominal cuyo núcleo aparece determinado por un mostrativo (aquel), representante de la distancia temporal del evento en que el participante estuvo involucrado, y por tres adjetivos calificativos sucesivos que proyectan la figura del participante de una forma bastante ilustrativa. Además, se lo llama "argentino" y la expresión, en este contexto de función sustantiva, representa sutilmente la perspectiva mental del español. En esa palabra aparece concentrada la producción de su diferencia básica (argentino vs. español), a la que se suman las demás (afeminado vs. varonil, vulnerable $v s$. invulnerable, frágil $v s$. fuerte).

Por lo demás, el atributo, también complejo estructuralmente, muestra una frase nominal cuyo elemento central es el sustantivo "escritor", calificado por una estructura nucleada en el adjetivo "digno", a su vez, modificado por estructuras preposicionales de función adjetiva en profundidad.

\section{CONCLUSIONES}

La lengua de los textos, sean estos literarios, críticos, pedagógicos, políticos o relativos a cualquier otra práctica cultural, muestra en su constitución las huellas de otros textos y discursos, los propósitos culturales que actualizan, los roles y el estatus de los participantes de la interacción en la que surgen, los valores de las ideologías que los cruzan.

El caso de Manuel Puig y de su obra es uno entre muchos otros. Si se logra demostrar cómo afectan los procesos de canonización y la constitución de monumentos culturales, estables o transitorios, las representaciones de la obra y de su autor, su aparición o ausencia dentro de otras discursividades, la red de relaciones sociales expresadas discursivamente en cada uno de los textos que nutren el sistema literario y el contexto cultural, se podrían, quizá, postular unos modelos de análisis que integren las 
distintas instancias y que muestren de forma clara los movimientos analíticos entre los diferentes estratos del análisis, es decir, que muestren la naturaleza sistémica de los procesos culturales y de sus productos naturales los textos y los discursos.

Hemos mostrado de manera incompleta, y con un corpus muy pequeño, un posible método de levantamiento de las matrices de significado representacional, interactivo e informativo que los discursos sedimentan por medio de la dialéctica entre producción y recepción discursivas, en torno a un fenómeno relevado de una cultura históricamente definida y podemos imaginar cómo estos significados, desplegados en toda su amplitud tridimensional se cruzan, interactúan y pugnan por conformar culturas de opinión y valoración, siempre inestables. En un segundo avance, se podrían exhibir de manera más amplia estas dinámicas, mediante el contraste de los textos y la ampliación del análisis a niveles registrales y genéricodiscursivos que aportarían una imagen más completa del fenómeno. A su vez, se podrían estudiar conjuntos más amplios de matrices autores-obras, períodos más extendidos y también un número de modalidades discursivas más abarcante y complejo.

Este breve texto pretende ser solo un ensayo de presentación de los problemas investigados y del posible método de avance en el estudio. Si solo fuera el caso de Puig el que se estudia, estaría pendiente, por ejemplo, una recopilación más completa de textos influyentes en la constitución de su participación canónica y un modelo que explique de manera clara la forma en que interactúan esos textos, el papel del paso del tiempo en esas relaciones, las posibles modificaciones internas de los distintos sistemas.

\author{
Universidad Católica del Maule * \\ Facultad de Ciencias de la Educación \\ Escuela de Pedagogía en Lengua Castellana \\ Av. San Miguel 3605, (Chile) \\ hsimunovic@ucm.cl \\ Universidad Católica del Maule ** \\ Facultad de Ciencias de la Educación \\ Escuela de Pedagogía en Lengua Castellana \\ Av. San Miguel 3605, (Chile) \\ dorostegui@ucm.cl
}

\title{
OBRAS CITADAS
}

Angenot et al. Teoría Literaria. México/Buenos Aires: Siglo XXI, $2^{\mathrm{a}}$ Ed., 2002. Barthes, Roland. "La muerte de un autor". El susurro del lenguaje. Barcelona: Paidós, 1987. Coyle, Martin et al. (Eds.). Encyclopedia of Literature and Criticism. London \& New York: Routledge, 1993. 
Donoso, José. Historia personal del “Boom”. Santiago de Chile: Andrés Bello, 1987 [1972]

Eco, Umberto. Apocalípticos e integrados. Barcelona: Lumen/Tusquets, 1999.

Even-Zohar, Itamar. "The 'Literary System"”, en Polysystem Studies Poetics Today 11:1 (1990): 27-44.

Foucault, Michel. “¿Qué es un autor?”. Entre filosofia y literatura. Obras esenciales I. Barcelona: Paidós, 1999.

Fuentes, Carlos. La nueva novela latinoamericana. México: Joaquín Mortiz, 1969.

Giordano, Alberto. "Manuel Puig: Micropolíticas literarias y conflictos culturales", en Boletín del Centro de Estudios de Teoría y Crítica Literaria Universidad de Rosario 5 (1996): 17-34.

Goytisolo, Juan. "Manuel Puig", en Tribuna, diario El País. 27 de julio de 1990. elpais.com/diario/1990/07/27/opinión/649029609_850215.html

Gunia, Inke. De la poesía a la literatura. El cambio de los conceptos en la formación del campo literario español del siglo XVIII y principios del XIX. Madrid: Iberoamericana, 2008.

Halliday, M.A.K. An introduction to functional grammar. London: Arnold. $2^{\mathrm{a}}$ Edition, 1994.

__ El lenguaje como semiótica social. México: FCE, 1982 [1978].

Halliday, M.A.K. \& M.I.M. Matthiessen. An introduction to functional grammar.

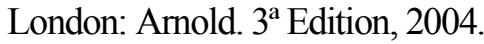

Maldonado Alemán, Manuel. "El pensamiento sistémico en la teoría literaria alemana I'. Revista de Filología Alemana 7 (1999): 15-60.

Meletinsky, Eleazar "Sociedades, cultura y hecho literario", en Angenot et al. Teoría Literaria. México/Buenos Aires: Siglo XXI Editores, $2^{\mathrm{a}}$ Ed., 2002: 17-35.

Oviedo, José Miguel. Historia de la literatura hispanoamericana. Tomo 4. De Borges al presente. Madrid: Alianza, 2002.

Piglia, Ricardo. Crítica y ficción. Buenos Aires: Planeta/Seix Barral, 2000.

Pozuelo Yvancos, J.M. y R.M. Aradra Sánchez. Teoría del canon literario y literatura española. Madrid: Cátedra, 2000.

Puig, Manuel. Boquitas Pintadas. Buenos Aires: Planeta, 2001.

Rodríguez Monegal, Emir. El boom de la novela latinoamericana. Caracas: Tiempo Nuevo, 1972.

Sheffy, Rakefet. "The Concept of Canonicity in Polysystem Theory". Poetics Today 11: 3 (Fall-1990): 511-522.

Schettini, Ariel. "Lectores argentinos de Manuel Puig", en La Biblioteca $N^{o}$ 4-5 (Verano-2006): 210-215.

Thibault, Paul J. Social Semiotics as Praxis: Text, Social Meaning Making, and Nabokov's Ada. NED-New Edition. Vol. 74. University of Minnesota Press, 1991. 
Tinianov, Iuri. "Sobre la evolución literaria", en Todorov Tzvetan. (Ed.). Teoría de la literatura de los formalistas rusos. Buenos Aires: Siglo XXI, 1965 [1927].

Todorov, Tzvetan (Ed.). Teoría de la literatura de los formalistas rusos. Buenos Aires: Siglo XXI, 1965.

Van Leeuwen, Theo. Introducing Social Semiotics. New York: Routledge, 2005.

Wischmann, Christine. "¿La literatura de masas reemplaza al escritor?", en Nueva Sociedad $N^{\circ} 6$ (Mayo-Junio 1973): 15-20.

Zubieta, Ana María. Cultura popular y cultura de masas: Conceptos, recorridos y polémicas. Buenos Aires, Barcelona y México: Paidós, 2000. 